\title{
RANCANG BANGUN ALAT PENGAMAN SEPEDA MOTOR MENGGUNAKAN GPS BERBASIS IOT
}

\author{
Hilal Indra Ramadhan', Affan Bachri², Zaenal Abidin ${ }^{3}$ \\ Prodi Teknik Elektro, Fakultas Teknik, Universitas Islam Lamongan \\ Jl. Veteran No.53 A, Lamongan \\ Telp. (0322)324706, Faks.(0322)324706 \\ E-mail: hilal.indra@gmail.com, avanbe@gmail.com, zainalabidin@unisla.ac.id
}

\begin{tabular}{ll}
\hline Article Info & \multicolumn{1}{c}{ ABSTRACT } \\
\cline { 3 - 3 } Article history: & $\begin{array}{l}\text { The developments of technology have penetrated into various fields including motorcycle safety. } \\
\text { The manufacturer's standard of locking system is not enough to protect the motor vehicles from } \\
\text { theft. Therefore, it requires a combination between software and hardware in creating additional }\end{array}$ \\
$\begin{array}{l}\text { Received July } 11^{\text {th }}, 2020 \\
\text { Revised August } 17^{\text {th }}, 2020\end{array}$ & $\begin{array}{l}\text { security systems. The purpose of this study is to design a motorcycle safety device by using IoT- } \\
\text { based GPS. The system is designed in order to control the motorcycle automatically turn the engine } \\
\text { off, sound the horn, and detect the location of motorcycle by smartphone with Blynk application }\end{array}$ \\
Accepted September $5^{\text {th }}, 2020$ & $\begin{array}{l}\text { when the robbery happened. Optocoupler sensor is a tool that uses to send a notification to Blynk } \\
\text { application when the motorcycle is stolen. It uses the Neo6mv2 GPS sensor as a coordinate sensor, }\end{array}$ \\
Keyword: & $\begin{array}{l}\text { NodeMCU V3 Microcontroller as a data processor and communication with a WiFi modem, Bolt } \\
\text { brand WiFI modem as a link to the internet network and Relay as a button that is controlled by the } \\
\text { NodeMCU }\end{array}$ \\
BoT & $\begin{array}{l}\text { Blynk application to turn on or turn off the engine, horn and turn signal. All of the components } \\
\text { require a supply } 5 \mathrm{~V} \text { voltage that generated by the motor ACCU 12V which is reduced to 5V by }\end{array}$ \\
Microcontroller & LM2596 module.
\end{tabular}

GPS tracker

Blynk

\begin{abstract}
Abstrak-Perkembangan teknologi telah merambah ke berbagai bidang termasuk pada pengaman motor. Sistem penguncian standar pabrikan dinilai tidak cukup untuk melindungi kendaraan bermotor dari pencurian. Dibutuhkan kombinasi antara perangkat lunak dan perangkat keras dalam menciptakan system keamanan tambahan. Tujuan dari penelitian ini untuk merancang bangun alat Pengaman Sepeda Motor Menggunakan GPS Berbasis IoT. Sistem yang dirancang pada saat terjadi perampasan yang dapat mematikan mesin, membunyikan klakson, dan mendeteksi lokasi sepeda motor yang dikendalikan melalui smartphone dengan aplikasi Blynk. Rancang bangun alat menggunakan sensor optocoupler untuk mengirim notifikasi ke aplikasi Blynk pada saat motor sedang dicuri. Menggunakan sensor GPS Neo6mv2 sebagai sensor koordinat, menggunakan Mikrokontroler NodeMCU V3 sebagai pengolah data dan komunikasi dengan modem WiFi, lalu menggunakan modem WiFi merk Bolt sebagai penghubung ke jaringan internet, dan menggunakan Relay sebagai tombol yang dikendalikan lewat aplikasi Blynk untuk menyalakan atau mematikan mesin, klakson, dan lampu sein. Semua komponen
\end{abstract}

membutuhkan supply tegangan sebesar $5 \mathrm{~V}$ yang dihasilkan dari Accu motor $12 \mathrm{~V}$ yang diturunkan jadi $5 \mathrm{~V}$ dengan modul LM2596.

\section{Kata-kata kunci: NodeMCU, IoT, mikrokontroler, GPS tracker, Blynk.}

\section{Pendahuluan}

Sepeda motor merupakan kendaraan yang paling banyak diminati di Indonesia. Alasan yang sering digunakan dalam pengguna sepeda motor adalah karena harga yang murah dan hemat bahan bakar. Sehingga motor dinilai sebagai alat transportasi yang efisien. Jumlah pengguna sepeda motor di Indonesia tercatat menyentuh angka 137.8 juta unit hingga tahun 2018. Semakin banyaknya pengguna sepeda motor bisa dilihat langsung di jalan raya, sepeda motor sudah memenuhi jalan-jalan di berbagai kota besar di Indonesia.

Menurut data dari Polda Metro Jaya, semakin banyaknya jumlah kendaraan bermotor juga diiringi dengan meningkatnya kejahatan terhadap pengguna sepeda motor. Dan yang sering terjadi adalah 
perampasan, atau dalam kata lain lebih sering dikenal dengan istilah begal. Polda Metro Jaya mencatat ada 81 kasus perampasan terjadi sepanjang Januari 2018 di wilayah hukumnya. 81 kasus itu tersebar di berbagai wilayah di Jakarta dan daerah-daerah penyangganya yaitu Depok, Tangerang, dan Bekasi.

Berbagai alasan pun diketahui mengapa para perampas melakukan tindakan itu. Salah satu alasan utama adalah Faktor ekonomi. Mereka biasa menjual motor hasil perampasan tersebut untuk digunakan sebagai biaya hidup sehari-hari karena banyak dari pelaku perampasan adalah pengangguran. Munculnya produk motor baru pada tiap tahunnya juga disinyalir menjadi pemicu aksi perampasan dikarenakan mereka ingin memiliki kendaraan tersebut tanpa harus mengeluarkan uang. Belum adanya pengaman sepeda motor pada saat kondisi dirampas pun membuat para perampas leluasa untuk membawa motor korban. Pada umumnya keamanan pada kendaraan masih bersifat pasif. Seperti kunci stang, penutup kunci dan sebagainya.

Banyak sumber yang membahas cara mengamankan diri dari tindak kejahatan perampasan motor. Diantaranya, pengendara harus mempersenjatai diri dengan senjata yang diperbolehkan seperti pepper spray. Menyiapkan handphone untuk melakukan panggilan darurat ke kantor polisi. Mencegah tindak perampasan dengan tidak melewati jalan yang sepi dan waktu yang larut malam, membiarkan perampas membawa motor untuk menghindari tindak kejahatan yang lebih parah seperti melukai atau bahkan membunuh korban. Namun dari semua cara di atas masih belum bisa mengatasi sepenuhnya.

Melihat permasalahan tersebut, penulis membuat alat sistem keamanan pada sepeda motor pada saat terjadi perampasan yang dapat mematikan mesin, membunyikan klakson, dan mendeteksi lokasi sepeda motor yang dikendalikan melalui smartphone.

\section{METODE PENELITIAN}

\section{A. Tahapan Penelitian}

\section{Adapun langkah-langkah yang digunakan dalam} penelitian ini adalah:

1. Membuat alat GPS tracker, pengirim notifikasi dan pengontrol relay dengan aplikasi Blynk.

2. Menganalisis kinerja pengontrol mesin, klakson dan sein dengan android.
3. Melakukan perhitungan akurasi titik koordinat GPS motor dibanding titik koordinat yang sebenarnya pada google maps.

\section{B. Alat dan Bahan yang digunakan}

Alat dan ba
1. NodeMCU V3

2. Modul GPS NEO6MV2

3. Modul Relay

4. Modul Stepdown LM2596

\section{Perancanaan}

Perencanaan merupakan suatu hal yang dilakukan untuk mempermudah proses pembuatan alat. Untuk menunjukkan alur kerja dari sebuah sistem, diperlukan sebuah konsep yang ditunjukkan oleh diagram blok berikut:

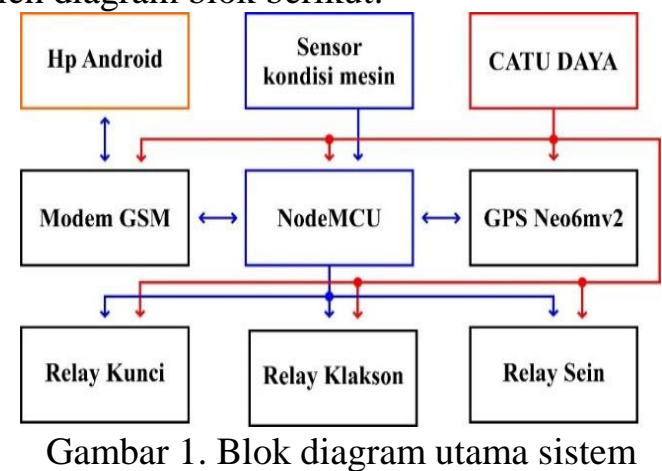

Berdasarkan diagram blok di atas dapat dijelaskan bahwa mobilephone digunakan untuk mengirim perintah dan menerima koordinat GPS dari Node MCU melalui Jaringan yang telah disediakn oleh aplikasi BLYNK, kemudian mikrokontroller Node MCU akan melakukan eksekusi untuk mengkaktifkan atau mematikan Relay. Kemudian GPS akan mencari koordinat lokasi dari setelit yang kemudian dibaca oleh mikrokontroller Node MCU, Setiap 1 detik sekali. Dan bisa dilihat kordinat tersebut secara real time pada aplikasi Blynk di androd. Dan juga dilengkapi dengan sensor kondisi motor, jika terjadi pencurian yang mesin motor dinyalakan maka alat ini akan mengirim notifikasi ke penggunanya.

Untuk menampilkaan koordinat lokasi, maka Arduino akan mengirim hasil koordinat dari GPS ke smartephone melalui Jaringan IoT yang disediakan oleh aplikasi Blynk. Yang dalam aplikasi Blynk ini ada widget yang digunakan untuk menampilkan peta lokasi GPS.

Pada dasarnya setiap perintah akan dilakukan melalui aplikasi Blynk yang sudah didisain untuk alat 
ini. Dan berikut merupakan daftar widget yang digunakan pada sistem tersebut:

1. Widget map, digunakan untuk menampilkan peta lokasi GPS.

2. Tombol Sein, digunakan untuk menyalakan dan mematikan lampu sein atau riting.

3. Tombol Matkan Mesin, digunakan untuk mematikan dan menyalakan pengapian motor.

4. Tombol Klakson, digunakan untuk menyalakan dan mematikan klakson.

\section{Desain alat}

Rangkaian secara skema keseluruhan yang diaplikasikan dalam kegiatan dapat dilihat dalam Gambar 2.

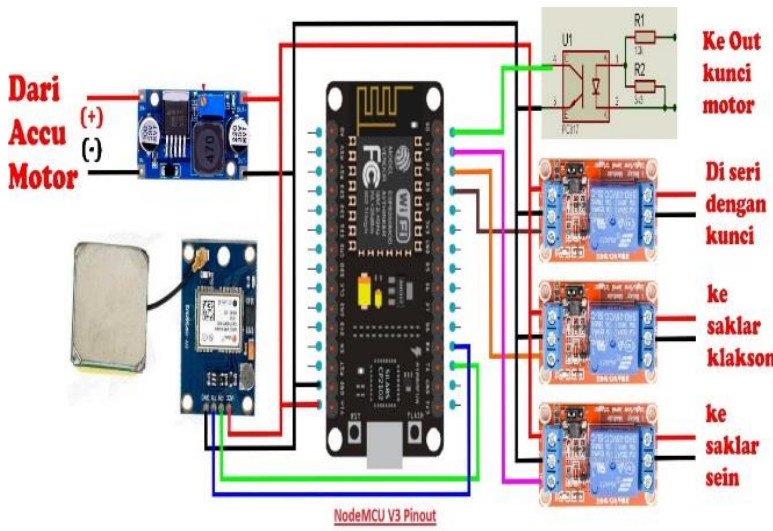

Gambar 2. Skema rangkaian keseluruhan

Flowchart system pemrograman mikrokontroller dapat dilihat dalam Gambar 3.

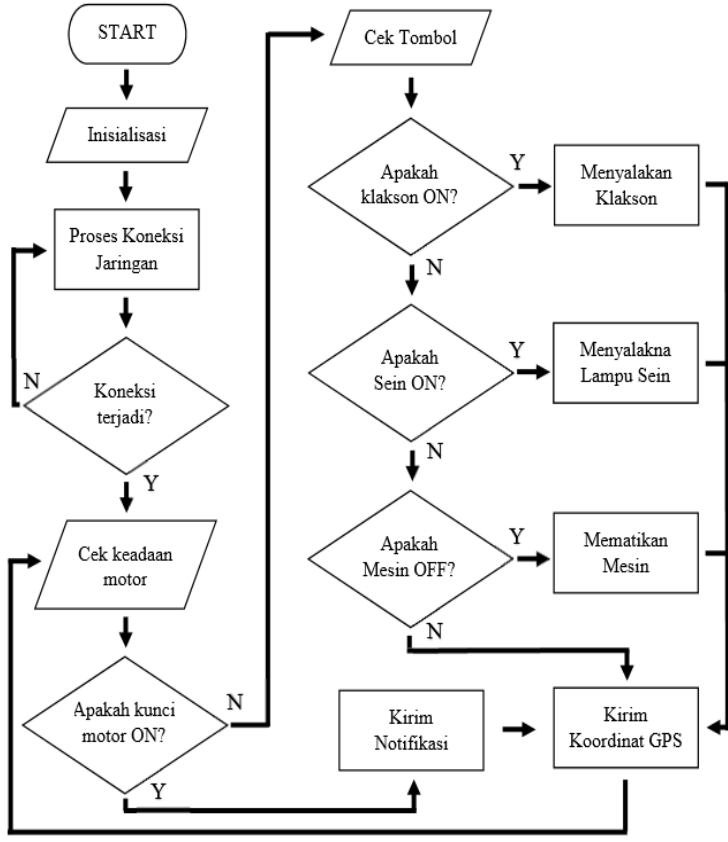

Gambar 3. Flowchart system pemrograman mikrokontroller

Desain software aplikasi Blynk dapat dilihat dalam

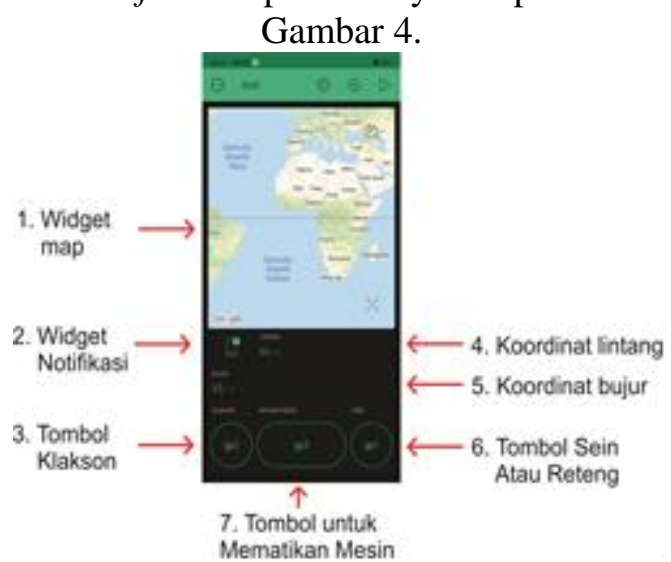

Gambar 4. Tampilan aplikasi Blynk

\section{HASIL DAN PEMBAHASAN}

A. Hasil penelitian

1) Pengujian Tombol Mesin, Klakson Dan Sein

Motor Dengan HP

Fitur ini dibuat agar saat motor sedang dicuri maka mesin sepeda motor dapat dimatikan dengan HP pemilik dari jarak jauh. Sehingga Pengujian ini dilakukan dengan cara membawa motor ke beberapa lokasi lalu menekan tombol yang ada pada aplikasi Blynk di HP yaitu tombol "MATIKAN MESIN" untuk mematikan mesin walau kontak motor menyala, tombol "KLAKSON" untuk membunyikan klakson, tombol "SEIN" untuk menyalakan lampu Sein . 
Tabel 1. hasil pengujian tombol mematikan mesin, klakson dan sein.

\begin{tabular}{|ccccc|}
\hline NO & LOKASI & $\begin{array}{c}\text { MATIKAN } \\
\text { MESIN }\end{array}$ & KLAKSON & SEIN \\
\hline & Di Jalan & & & \\
raya & & & \\
& menongo \\
1 & depan pasar & BERHASIL & BERHASIL & BERHASIL \\
& desa & & \\
& menongo & & \\
& sukodadi & & \\
\hline & Di Depan & & & \\
& SD Negeri \\
desa & & & \\
menongo & BERHASIL & BERHASIL & BERHASIL \\
& kecamatan & & \\
& & & \\
\hline
\end{tabular}

\begin{tabular}{|c|c|c|c|}
\hline 3 & $\begin{array}{c}\text { Di Jalan } \\
\text { Airlangga } \\
\text { sukodadi } \\
\text { lamongan, } \\
\text { depan pintu } \\
\text { masuk } \\
\text { kampus } \\
\text { UNISDA } \\
\text { Lamongan }\end{array}$ & BERHASIL BERHASIL & BERHASIL \\
\hline 4 & $\begin{array}{c}\text { Di jembatan } \\
\text { perbatasan } \\
\text { desa } \\
\text { menongo } \\
\text { dan desa } \\
\text { jirekan } \\
\text { sukodadi } \\
\text { lamongan }\end{array}$ & BERHASIL BERHASIL & BERHASIL \\
\hline 5 & $\begin{array}{l}\text { Di jalan } \\
\text { raya } \\
\text { sumberaji } \\
\text { depan } \\
\text { gerbang } \\
\text { SMP N 1 } \\
\text { Sukodadi } \\
\text { Lamongan }\end{array}$ & BERHASIL BERHASIL & BERHASIL \\
\hline 6 & $\begin{array}{c}\text { Di jembatan } \\
\text { jalan raya } \\
\text { sugio - } \\
\text { baturono } \\
\text { Sukodadi } \\
\text { Lamongan } \\
\end{array}$ & BERHASIL BERHASIL & BERHASIL \\
\hline 7 & $\begin{array}{c}\text { Di depan } \\
\text { masjid AL- } \\
\text { MUSTAJA } \\
\text { BAH desa } \\
\text { banjarejo } \\
\text { Sukodadi } \\
\text { Lamongan }\end{array}$ & BERHASIL BERHASIL & BERHASIL \\
\hline
\end{tabular}

Dari tabel pengujian di atas, menunjukkan bahwa semua tombol kendali pada aplikasi Blynk seperti matikan mesin, klakson, dan lampu sein walau pada lokasi yang berbeda masih berfungsi dengan baik.

\section{2) Pengujian GPS tracker}

Pengujian ini digunaka aplikasi Blynk pada smartphone android untuk menampilkan peta map dan titik lokasi GPS motor. Pengujian sendiri dilakukan di beberapa lokasi untuk mendapatkan data yang tepat. Kemudian data yang diperoleh dari GPS motor akan dibandingkan dengan titik koordinat lokasi kita berada pada google map. Adapun hasil yang diperoleh dapat dilihat seperti gambar dibawah ini.

1. Pengambilan dilakukan dilokasi jalan raya menongo depan pasar desa menongo Sukodadi
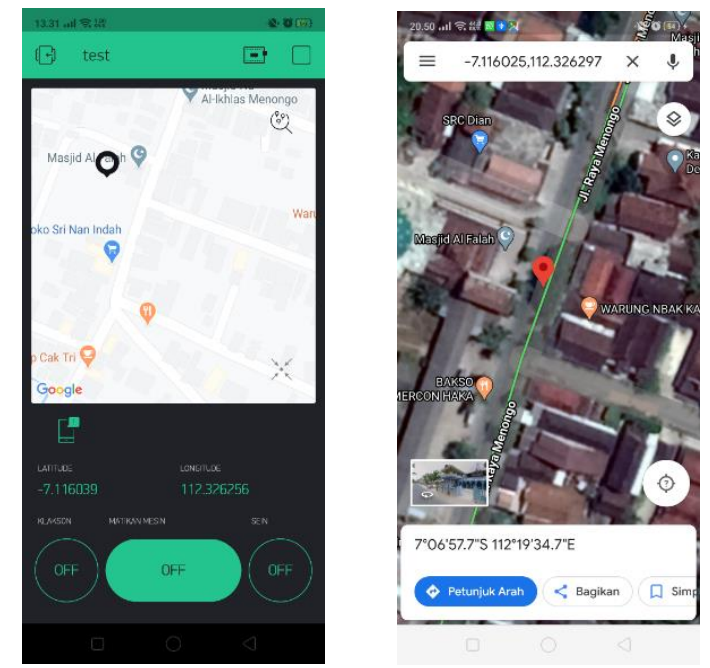

Gambar kiri menunjukkan bahwa koordinat lokasi yang diterima oleh GPS dan dikirimkan kepada pengguna melalui BLYNK adalah lintang -7.116039, bujur 112.326256. dan gambar kanan adalah tempat lokasi pengambilan yang ditandai melalui aplikasi google maps adalah lintang -7.116025, bujur 112.326279.

Dari hasil pengujian diatas, didapat beberapa koordinat yang diambil dari 7 lokasi yang berbeda. Dan koordinat yang telah didapat akan digunakan untuk menghitung tingkat akurasi dari modul GPS alat ini. Berikut adalah perhitungannya.

Diketahui :

$>$ Koordinat GPS Motor lokasi 1: Lat 1 -7.116039 Long $_{1} 112.326256$ 


\begin{tabular}{|c|c|c|c|c|}
\hline $\mathrm{NO}$ & Lokasi & $\begin{array}{l}\text { Koordinat } \\
\text { Gps Motor } \\
\text { Latiuide } \\
\text { Longitued }\end{array}$ & $\begin{array}{c}\text { Koordinat } \\
\text { Google Map } \\
\text { Latiuide } \\
\text { Longitued }\end{array}$ & $\begin{array}{c}\text { Hasil } \\
\text { Selisih } \\
\text { (Meter) }\end{array}$ \\
\hline 1 & $\begin{array}{c}\text { Di Jalan raya } \\
\text { menongo depan } \\
\text { pasar desa } \\
\text { menongo } \\
\text { sukodadi }\end{array}$ & $\begin{array}{c}-7.116039 \\
112.326256\end{array}$ & $\begin{array}{c}-7.116025 \\
112.326279\end{array}$ & 2.99 \\
\hline 2 & $\begin{array}{l}\text { Di Depan SD } \\
\text { Negeri desa } \\
\text { menongo } \\
\text { kecamatan } \\
\text { sukodadi }\end{array}$ & $\begin{array}{c}-7.106995 \\
112.328804\end{array}$ & $\begin{array}{c}-7.106939 \\
112.328818\end{array}$ & 6.42 \\
\hline 3 & $\begin{array}{c}\text { Di Jalan } \\
\text { Airlangga } \\
\text { sukodadi } \\
\text { lamongan, } \\
\text { depan pintu } \\
\text { masuk kampus } \\
\text { UNISDA } \\
\text { Lamongan } \\
\end{array}$ & $\begin{array}{c}-7.095188 \\
112.332085\end{array}$ & $\begin{array}{c}-7.09521 \\
112.332082\end{array}$ & 2.47 \\
\hline 5 & $\begin{array}{c}\text { Di jalan raya } \\
\text { sumberaji depan } \\
\text { gerbang SMP N } \\
1 \text { Sukodadi } \\
\text { Lamongan }\end{array}$ & $\begin{array}{l}-7.130971 \\
112.33432\end{array}$ & $\begin{array}{c}-7.130969 \\
112.334342\end{array}$ & 2.44 \\
\hline 6 & $\begin{array}{c}\text { Di jembatan } \\
\text { jalan raya sugio } \\
\text { - baturono } \\
\text { Sukodadi } \\
\text { Lamongan }\end{array}$ & $\begin{array}{c}-7.138129 \\
112.339653\end{array}$ & $\begin{array}{c}-7.138115 \\
112.339656\end{array}$ & 1.59 \\
\hline 7 & $\begin{array}{c}\text { Di depan masjid } \\
\text { AL- } \\
\text { MUSTAJABAH } \\
\text { desa banjarejo } \\
\text { Sukodadi } \\
\text { Lamongan }\end{array}$ & $\begin{array}{c}-7.134798 \\
112.348877 \\
\end{array}$ & $\begin{array}{c}-7.134812 \\
112.349053\end{array}$ & 19.48 \\
\hline \multicolumn{4}{|c|}{ JUMLAH RATA - RATA SELISIH } & 5.22 \\
\hline
\end{tabular}

Koordinat lokasi sebenarnya pada google map : $\mathrm{Lat}_{2}$ -7.116025 - Long 112.326279

Ditanya jarak garis lurus antara GPS motor dengan lokasi sebenarnya pada google map ?

$$
\begin{aligned}
& \text { Jawab }: \frac{\sqrt{\left(\text { lat }_{1}-\text { lat }_{2}\right)^{2}+\left(\text { long }_{1}-\text { long }_{2}\right)^{2}}}{\text { Jarak }}=\sqrt{(-7.116039-(-7.116025))^{2}} \\
& \text { Jarak }=\sqrt{(112.326256-112.326279)^{2}} \\
& \text { Jarak }=\sqrt{1.96 \times 10^{-10}+\left(5.29 \times 10^{-10}\right)}
\end{aligned}
$$

Jarak $=\sqrt{7 \times 10^{-10}}$

Jarak $=2.692 \times 10^{-5}$ x 111319 meter $(1$ derajat bumi $=111.319 \mathrm{~km}$ )

Jarak $=2.997$ Meter

Jadi jarak secara garis lurus antara GPS motor dengan lokasi sebenarnya padaggole map adalah 2.997 Meter.

Tabel 2. perhitungan keakuratan GPS dengan rumus koordinat Euclidean.

Dari tabel pengujian diatas, menunjukkan bahwa alat ini dapat melacak koordinat GPS motor dengan baik. Namun masih memiliki toleransi keakuratan dengan rata-rata 5.22 meter.

\section{KESIMPULAN}

Setelah melalui tahap perancangan, pengujian dan pembahasan hasil pengujian secara keseluruhan maka dapat diambil beberapa kesimpulan sebagai berikut yaitu :

1. Perancangan alat pengaman sepeda motor dengan GPS berbasis IoT menggunakan beberapa komponen yaitu sensor optocoupler sebagai sensor kondisi kontak motor ON/OFF dan sensor GPS Neo6mv2 sebagai sensor koordinat, menggunakan Mikrokontroler NodeMCU V3 sebagai pengolah data dan komunikasi dengan modem WiFi, lalu menggunakan modem WiFi merk Bolt sebagai penghubung ke jaringan internet, dan menggunakan Relay sebagai tombol yang dikendalikan untuk menyalakan atau mematikan mesin, klakson, dan lampu sein. Semua komponen membutuhkan supply tegangan sebesar $5 \mathrm{~V}$ yang dihasilkan dari Accu motor $12 \mathrm{~V}$ yang diturunkan jadi 5V dengan modul LM2596.

2. Dari hasil pengujian bahwa perancangan alat pengaman sepeda motor dengan GPS berbasis IoT ini berjalan dan bekerja dengan baik dan Secara sistem, alat sudah dapat bekerja dengan baik dan sesuai dengan konsep yang direncanakan yaitu dapat mematikan motor dengan aplikasi android Blynk, menyalakan lampu sein, membunyikan klakson dan mengecek lokasi sepeda motor. Dalam uji coba berhasil mengirim notifikasi pemberitahuan bahawa motor menyala di beberapa lokasi yang berbeda, berhasil mengontrol lampu sein, klakson, dan mematikan mesin di beberapa lokasi yang 
3. berbeda, dan berhasil mengirim lokasi sepeda motor dengan tracking GPS didapat keakuratan GPS dengan hasil rata - rata 5.22 Meter.

\section{Saran}

Berdasarkan pengalaman pada penelitian ini disarankan untuk peneliti selanjutnya :

1. Disarankan menggunakan sensor GPS dengan type lain yang lebih cepat dalam loading start ON karena modul GPS Neo6mv2 ini memiliki kekurangan yaitu pertama kali dinyalakan harus menunggu sekitar 1 menit baru bisa mendeteksi data koordinat..

2. Diperlukan pendalaman lebih lanjut tentang Internet Of Thinks agar bisa connect internet tanpa modem wifi tambahan.

3. Peletakan komponen bisa lebih dibuat rapat sehingga tidak memakan banyak ruang dan alat bisa dibuat lebih kecil.

4. Pada program Microcontroller sebaiknya ditambahkan fitur fitur lain yang dibutuhkan supaya memudahkan pengguna seperti cek sisa kuota sehingga pengguna dapat mengetahui sisa kuota internet dari SIM yang ada pada alat.

\section{PUSTAKA}

[1.] Andy, Fitrivanto Pratama. 2017. System pengaman sepeda motor menggunakan sensor FSR (Force Sensitive Resistor), Mikrokontroller Arduino uno dan modul SIM800L. Universitas Negeri Sunan Kalijaga Yogyakarta.

[2.] Arafat. 2016. Sistem Pengamanan Pintu Rumah Berbasis Internet Of Things (IoT) Dengan ESP8266. Jurnal Ilmiah Fakultas Teknik "Technologia".

[3.] Dony, Kurnia Aji. 2018. Sistem Pengaman Sepeda Motor Dengan Arduino Berbasis Android. Universitas Muhammadiyah Surakarta.

[4.] Modul GPS Neo6mv2. Diambil pada tanggal 22 Mei 2020 dari https://www.cytron.io/p-gyneo6mv2-flight-control-gps-module, 2016.

[5.] NodeMCU V3. Diambil pada tanggal $20 \mathrm{Mei}$ 2020 dari http://Gado-Gadonya YOPI ARDINAL - WordPress.com,2019.

[6.] Rangkaian Regulator Dengan Rangkaian LM2596/Lm2576 Arus 3A. Diambil pada tanggal $22 \quad$ Mei $2020 \quad$ dari https://mikroavr.com/rangkaian-regulator-lm2596$\operatorname{lm} 2576$.
[7.] Suharijanto, Affan Bachri. 2018. Rancang Bangun Sistem Keamanan Sepeda Motor Dengan Fingerprint Berbasis Telephone.. Universitas Islam Lamongan.

[8.] Teori HArversine Formula. Diambil pada tanggal 23 mei $2020 \quad$ dari https://blogs.itb.ac.id/anugraha/2014/09/10/teoripengukuran-jarak.

[9.] Teori Relay Elektro Mekanik. Diambil pada tanggal 22 mei 2020 dari http://elektronikadasar.web.id

[10.] Thoyyib, Muhammad Miftahuddin. 2017. System Keamanan Sepeda Motor Dari Perampasan Menggunakan Sms Dan Gps Berbasis Arduino Nano. Universitas Negeri Yokykarta. 